\title{
Tailings Management to Optimise Water Losses
}

\author{
A. Robertson Robertson GeoConsultants Inc., Canada
}

\begin{abstract}
The reduction of the water content of a tailings slurry may be referred to as 'dewatering' or 'water removal' as is done when water is separated by mechanical means such as thickening or the production of paste tailings, or as 'water loss', when natural processes of drying, seepage and entrainment remove water. Often the context is such that water removed by dewatering or water removal is available for re-use and water lost is not. Optimisation of water losses from tailings may involve either a minimisation of water losses, as may be desirable in areas where water is scarce, or maximisation of losses, such as may be an advantage when a dryer tailings product is more stable, allowing stacking and reducing the long term need for containment in a dam. A review is made of methods for water removal and methods for both maximising and minimising water losses. Illustrations are provided of tailings management systems in which both water removal and management of water losses are practiced in order to meet differing objectives of water recovery and development of stable tailings deposits. The factors that influence the efficiency and effectiveness of both water removal and losses are discussed, including clay content of tailings, placement management methods and the influence of climate from hot deserts to frigid tundra (evaporation, desiccation and ice entrainment). Some examples are provided of typical water losses achieved for different tailings types, different dewatering methods and different tailings distribution and management methods. A review is made of some of the issues that may arise with different tailings management systems ranging from mechanically dewatered (dry) and placed tailings, through partially dewatered (paste) tailings to evaporation dried stacked tailings to slurry deposits.
\end{abstract}

Approval to publish this paper was not received prior to these proceedings going to print. This paper will be made available on the Internet on the ACG website, www.acg.uwa.edu.au, and at the following URL:

http://www.infomine.com/publications/docs/TailingsOptimisation2009.pdf 